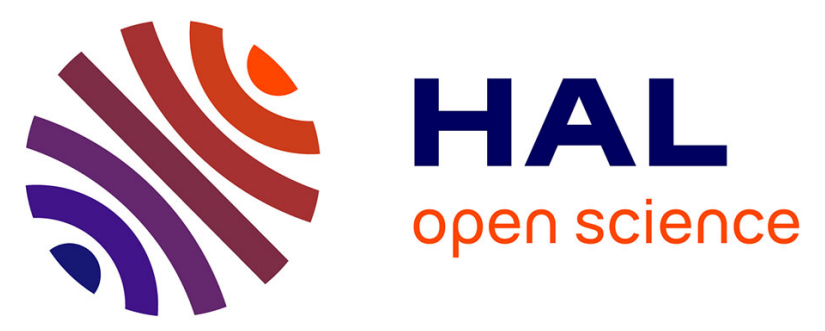

\title{
Monodisperse Oil-in-Water Emulsions Stabilized by Proteins: How To Master the Average Droplet Size and Stability, While Minimizing the Amount of Proteins
}

Wafa Dridi, Christelle Harscoat-Schiavo, Julien Monteil, Chrystel Faure, Fernando Leal-Calderon

\section{To cite this version:}

Wafa Dridi, Christelle Harscoat-Schiavo, Julien Monteil, Chrystel Faure, Fernando Leal-Calderon. Monodisperse Oil-in-Water Emulsions Stabilized by Proteins: How To Master the Average Droplet Size and Stability, While Minimizing the Amount of Proteins. Langmuir, 2018, 34 (31), pp.9228-9237. 10.1021/acs.langmuir.8b02029 . hal-02356392

\section{HAL Id: hal-02356392 https://hal.science/hal-02356392}

Submitted on 21 Feb 2021

HAL is a multi-disciplinary open access archive for the deposit and dissemination of scientific research documents, whether they are published or not. The documents may come from teaching and research institutions in France or abroad, or from public or private research centers.
L'archive ouverte pluridisciplinaire HAL, est destinée au dépôt et à la diffusion de documents scientifiques de niveau recherche, publiés ou non, émanant des établissements d'enseignement et de recherche français ou étrangers, des laboratoires publics ou privés. 
This document is confidential and is proprietary to the American Chemical Society and its authors. Do not copy or disclose without written permission. If you have received this item in error, notify the sender and delete all copies.

\section{Highly monodisperse $0 / \mathrm{W}$ emulsions stabilized by proteins: how to master the average droplet size and stability, while minimizing the amount of proteins}

\begin{tabular}{|r|l|}
\hline Journal: & Langmuir \\
\hline Manuscript ID & la-2018-020297 \\
\hline Manuscript Type: & Article \\
\hline Date Submitted by the Author: & 17-Jun-2018 \\
\hline Complete List of Authors: & $\begin{array}{l}\text { DRIDI, Wafa; Université de Bordeaux, CBMN UMR 5248 } \\
\text { Harscoat-Schiavo, Christelle; CBMN UMR -CNRS 5248, } \\
\text { MONTEIL, Julien; Université de Bordeaux, CBMN UMR 5248 } \\
\text { Faure, Chrystel; Chimie et Biologie des membranes et Nano-objets, CNRS, } \\
\text { UMR5248 } \\
\text { Leal-Calderon, Fernando; Bordeaux INP, CBMN UMR 5248 }\end{array}$ \\
\hline
\end{tabular}




\title{
Highly monodisperse $\mathrm{O} / \mathrm{W}$ emulsions stabilized by proteins: how to master the average
} droplet size and stability, while minimizing the amount of proteins

\author{
Wafa Dridi $^{1,2,3}$, Christelle Harscoat-Schiavo ${ }^{1,2,3}$, Julien Monteil ${ }^{1,2,3}$, Chrystel Faure ${ }^{1,2,3}$, \\ Fernando Leal-Calderon ${ }^{1,2,3}$ \\ ${ }^{1}$ Univ. Bordeaux, CBMN, UMR 5248, 33600 Pessac, France \\ ${ }^{2}$ CNRS, CBMN, UMR 5248, 33600 Pessac, France \\ ${ }^{3}$ Bordeaux INP, CBMN, UMR 5248, 33600 Pessac, France \\ * Corresponding author: \\ Fernando LEAL-CALDERON; fleal@enscbp.fr, +33 540006692 \\ Address: ENSCBP, 16 Av. Pey-Berland, 33600 PESSAC, FRANCE
}




\section{Abstract}

Hexadecane-in-water emulsions were fabricated by means of a microfluidizer using two types of protein stabilizers, sodium caseinate (NaCAS) and beta-lactoglobulin (BLG). A study of the dependence of the mean droplet diameter and protein coverage on protein concentration was performed. At low protein concentrations, the emulsions were highly monodisperse and their mean droplet size was governed by the so-called limited-coalescence process. In this regime, the interfacial coverage was constant and was deduced from the linear evolution of the total interfacial area as a function of the amount of adsorbed proteins. In emulsions based on $\mathrm{NaCAS}$, almost all the initial protein content was adsorbed at the interfaces. Emulsions formulated at very low protein content underwent unlimited coalescence after prolonged storage or when submitted to centrifugation. Additional NaCAS was incorporated in the continuous phase, right after the emulsification process, as a means of ensuring kinetic stability. The interfacial coverage increased after protein addition. Other strategies including acidification and salt addition were also probed to gain stability. Instead, in emulsions based on BLG, only partial adsorption of the initial protein content was observed. The corresponding emulsions remained kinetically stable against coalescence and no further addition of protein was required after emulsification. Our approach allows to obtain highly monodisperse, kinetically stable emulsions, and to master their average droplet size, while minimizing the amount of proteins. 
Graphical abstract

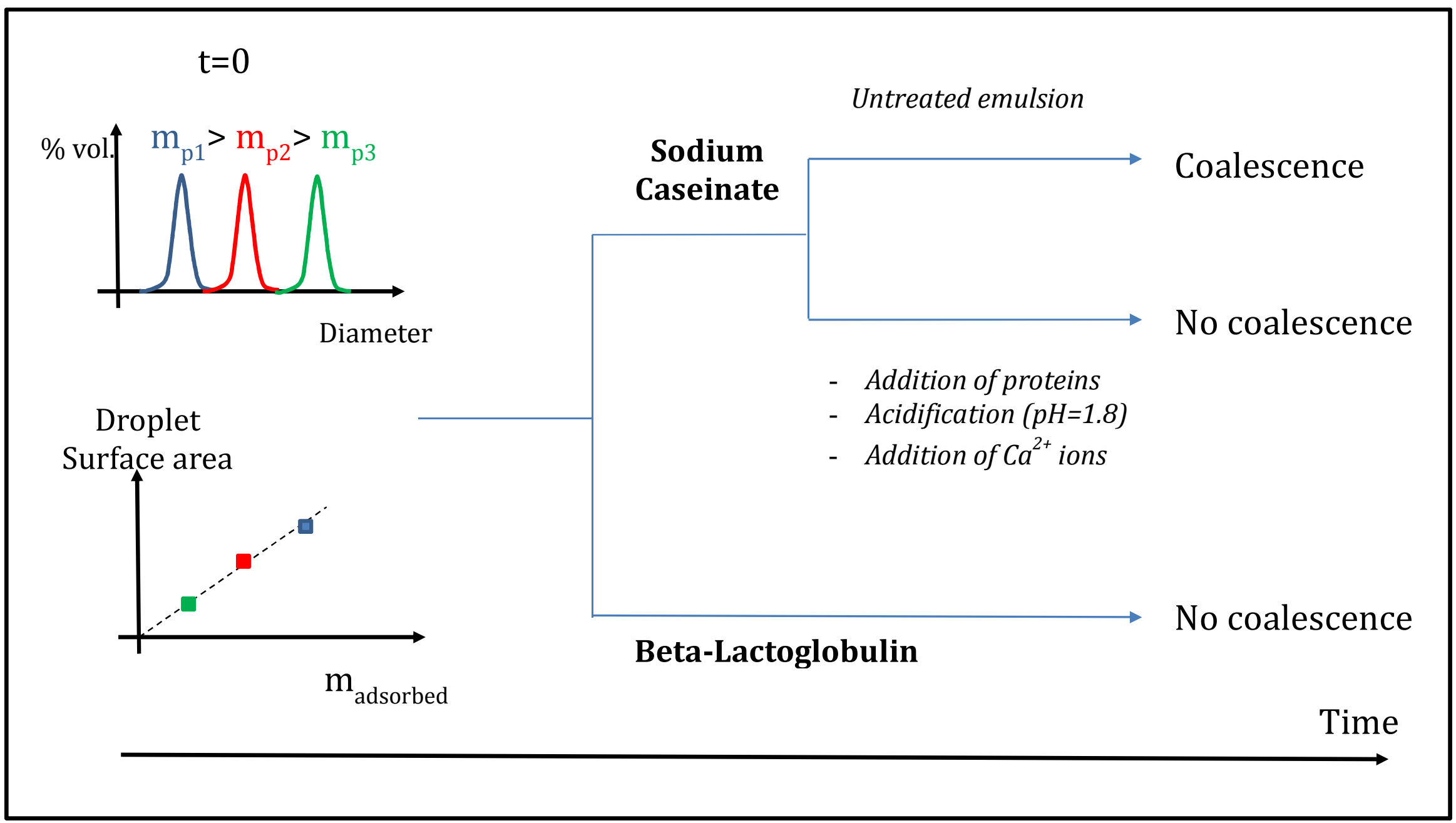




\section{Introduction}

Emulsions are complex systems generally composed of oil, water and emulsifiers. A liquid phase is dispersed in another immiscible one through mechanical shear, the oil-water interfaces being covered by emulsifiers. Proteins are emulsifiers made of polar and non-polar amino acid residues. When a protein adsorbs at the oil-water interface, its hydrophobic regions created by clusters of non-polar amino acid side chains, lie on, or partially penetrate the oil phase. Proteins can be used as emulsifiers because of their ability to facilitate the formation, to ensure kinetic stabilization and to control the rheological properties of oil-inwater $(\mathrm{O} / \mathrm{W})$ emulsions ${ }^{1}$. Once proteins are adsorbed at the interface, they lower the interfacial tension and they form a protective membrane. In the case of emulsions, this membrane generates repulsive interactions (steric and/or electrostatic) ${ }^{2}$ between oil droplets, and also plays an important role in stabilizing the droplets against flocculation and coalescence during long-term storage.

Milk proteins are among the most widely used proteins for the formulation of $\mathrm{O} / \mathrm{W}$ emulsions. They are mainly used as ingredients in the food arena ${ }^{3}$. In the present study, we will focus on the behavior of emulsions stabilized by two different proteins: $\beta$-lactoglobulin (BLG) and sodium caseinate (NaCAS). BLG $\left(\mathrm{M} \approx 18300\right.$ g. $\left.\mathrm{mol}^{-1}\right)$ is a whey protein, existing in several variants, A and B being the most important ones ${ }^{4}$. BLG has one buried SH-group which becomes accessible upon unfolding. In contrast, NaCAS $(M \approx 20000)$ is a random coil protein $^{4,5}$ with limited secondary structure, commonly considered as a model flexible polyelectrolyte ${ }^{6}$. NaCAS can easily form interfacial layers from aqueous solutions because of its random coil nature and its ability to form intermolecular bonds, resulting in an increase of the inter-chain cohesion ${ }^{7}$. Additionally, the excellent adsorption of sodium caseinate at the interface is a consequence of its flexibility and the considerable number of hydrophobic 
residues present in these proteins ${ }^{8}$. NaCAS exists as a mixture of 4 monomers ( $\alpha$ s1-, $\alpha$ s-, $\beta-$ and $\kappa$-casein) $)^{3}$ and has the ability to form "micellar" aggregates 9 .

Proteins can undergo a glass or gel transition due to a macromolecular packing at the interface even for low bulk concentrations in the aqueous phase ${ }^{5}$. The interfacial concentration is generally of the order of several mg. $\mathrm{m}^{-2}{ }^{10}$. The adsorption of proteins at fluid-fluid interfaces is generally followed by gradual unfolding. In this process, proteins lose their secondary and higher structure in the adsorbed state. Unfolding uncovers different segments of adsorbed species, which facilitates lateral interactions of various types between the adsorbed molecules: ionic, hydrophobic, covalent (disulfide bridging) or hydrogen bonding. As a result, the adsorbed protein layers which protects the droplets against coalescence are viscoelastic, and almost always tangentially immobile ${ }^{11,12}$. When dealing with proteins, equilibrium adsorption can be ruled out for many reasons ${ }^{2}$. Firstly, the presence of many adsorption sites per molecule makes the desorption process unlikely. Secondly, unfolding is irreversible, i.e. desorbed species do not recover the conformation and structure they had in bulk, prior to adsorption. Thirdly, protein adsorption may lead to multilayer formation $^{13,14}$. Multilayers are made of reversibly adsorbed molecules or protein aggregates and the interfacial coverage can be increased up to $5-10 \mathrm{mg} \cdot \mathrm{m}^{-2} 15$.

The final droplet size distribution obtained after an emulsification process is a result of a dynamic equilibrium between droplet break-up and coalescence. Both processes are favored by the intense agitation during emulsion formation ${ }^{16,17}$. The evolution of the drop size distribution under shear depends on many variables related to the emulsification conditions (mixing geometry, duration, temperature, etc.) and to the nature and concentration of the emulsifier (kinetics of adsorption, interfacial tension, diffusion coefficient, etc.), which in turn determine the interactions between the interfaces and the energy barrier to coalescence ${ }^{17-19}$. Ideally, the emulsifier should rapidly adsorb to the freshly formed droplets surfaces, reduce 
the interfacial tension to facilitate droplet break-up, and generate long-range repulsive forces between the interfaces to prevent aggregation and coalescence. Proteins differ each other in the rate at which they adsorb to droplet surfaces, in the interfacial coverage, in the viscoelastic properties of the interfacial film and in their ability to protect droplets against coalescence ${ }^{10,20}$. The total amount of protein also plays a major role in determining the average droplet size during homogenization and in imparting stability. Two regimes have been identified so $\operatorname{far}^{10}$ :

Low protein content. When the amount of emulsifier is insufficient to fully cover the droplet surface area created by the homogenizer, then the droplet size is governed by protein concentration. After the processing step, the partially unprotected droplets coalesce, thus reducing the total amount of oil-water interface. Since proteins are irreversibly adsorbed, coalescence is halted once the oil-water interface is sufficiently covered. The final interfacial coverage remains constant in this regime. Assuming that the entire amount of proteins is adsorbed on the drop surface and that interfacial coverage corresponds to the threshold value for obtaining stable emulsions, $\Gamma$ (in $\mathrm{kg} \cdot \mathrm{m}^{-2}$ ), the surface-averaged diameter of the droplets, $d_{32}$, is given by:

$$
d_{32}=\frac{6 \phi \Gamma}{(1-\phi) C_{P r}^{0}}
$$

where $\phi$ is the disperse phase volume fraction and $C_{P r}^{0}\left(\right.$ in $\left.\mathrm{kg} \cdot \mathrm{m}^{-3}\right)$ is the initial concentration of protein in the aqueous phase. The phenomenon described here is reminiscent of the socalled limited coalescence process observed in emulsions stabilized by colloidal particles, at low particle concentration ${ }^{21,22}$.

High protein content. When the protein concentration is larger than that required to completely cover the droplets surface area, the mean droplet size is weakly dependent on the emulsifier concentration and is mainly determined by the density power of dissipation in the emulsification device. If proteins do not form multiple layers at the interface, the interfacial coverage, $\Gamma$, remains almost constant in this regime. Conversely, if the emulsifier is prone to 
forming multiple layers at the interface, the interfacial coverage may increase as the overall protein concentration in the system is increased. Such situation has been observed in the presence of whey proteins ${ }^{10}$.

As most of the physico-chemical properties (stability, rheology, elasticity of dense emulsions) ${ }^{23}$ and end-use properties (sensorial, organoleptic) of emulsions depend on their average droplet size, controlling this parameter is a key issue. In this study, we propose an approach to obtain highly monodisperse, kinetically stable emulsions, and to master their average droplet size, while minimizing the amount of proteins. To this end, we exploit the limited coalescence process at low protein content that allows obtaining emulsions with very narrow size distributions. We prepare hexadecane-in-water emulsions stabilized by two types of proteins, NaCAS and BLG. We show that the interfacial coverage right after the emulsification process is, in some cases, insufficient to ensure longstanding kinetic stabilization. For such systems, we propose several strategies to gain stability against coalescence including addition of free protein in the continuous phase right after the emulsification process, acidification and salt addition.

\section{Experiments}

\subsection{Materials}

All chemicals employed in the present study were from Sigma (France) and were used as received. The proteins used were sodium caseinate (NaCAS) and $\beta$-lactoglobulin (BLG). Hexadecane (puriss; density $=0.773 \mathrm{~g} . \mathrm{cm}^{-3}$ ) was chosen for the oil phase. In all samples, the aqueous phase contained 0.01 mol. $\mathrm{L}^{-1} \mathrm{NaN}_{3}$ (reagentplus ${ }^{\circledR}>=99.5 \%$ ), to prevent bacterial growth. Bradford reagent was used for protein quantification. Sodium dodecyl sulfate (SDS) was adopted as an emulsifier to dilute emulsions before droplet size measurements. Sodium 
chloride, $\mathrm{NaCl}$, and hydrated calcium chloride, $\mathrm{CaCl}_{2} \cdot 2 \mathrm{H}_{2} \mathrm{O}$ (purity $>=99.5 \%$ ), were incorporated in the aqueous phase of some emulsions. A solution of hydrogen chloride $(\mathrm{HCl})$ at 1 mol. $\mathrm{L}^{-1}$ was prepared to adjust $\mathrm{pH}$ in some cases. All aqueous solutions were prepared with deionized water, purified by a PureLab ELGA water system (England).

\subsection{Methods}

\subsubsection{Emulsion Preparation}

$\mathrm{O} / \mathrm{W}$ emulsions were prepared by using a two-step procedure. Initially, $25 \mathrm{~g}$ of a premix at an oil fraction of $20 \mathrm{wt} . \%$ was prepared by means of an Ultra-turrax ${ }^{\circledR} \mathrm{T}-25$ disperser (IKA, Germany) operating at $3000 \mathrm{rpm}$ for $5 \mathrm{~min}$. The protein concentration in the aqueous phases ranged from 0.1 to $2 \mathrm{wt} . \%$. The second homogenization step was accomplished by passing this premix through a microfluidizer (Microfluidics M110S, Massachusetts, USA) at a pressure of 800 bars. A closed loop was used to ensure multiple passes of the emulsion through the microfluidizer. The passage through the homogenizing chamber provokes sample warming. The device was thus equipped with a metallic coil immersed in a cold-water bath (8 $\left.{ }^{\circ} \mathrm{C}\right)$ to maintain the average temperature around $25^{\circ} \mathrm{C}$ and to avoid thermal protein denaturation. The number of passes, namely 8 , was sufficient for reaching the steady state of the droplets size distribution. Emulsions obtained in that way possessed narrow size distributions and their mean size (diameter) was reproducible. Once fabricated, they were stored at room temperature $\left(25^{\circ} \mathrm{C}\right)$. Unless otherwise specified, we worked at the natural $\mathrm{pH}$ of the proteins, which was close to 6.0 for BLG, and 6.1 for NaCAS.

\subsubsection{Emulsion characterization}

Direct observation of the oil droplets just after preparation and over time was carried out using an optical microscope (Olympus BX51 (Olympus, Germany) equipped with a digital 
color camera (Leica, $2576 \times 1932$-pixel resolution) for image capturing.

The droplet size distributions were determined by static light-scattering, using a Mastersizer 2000 Hydro SM from Malvern Instruments S.A (Malvern, UK). The refractive indices were set at 1.43 for hexadecane and 1.33 for water. The droplet size distributions were described in terms of their surface-averaged diameter, $\mathrm{d}_{32}$, and polydispersity, $P$, defined as:

$$
d_{32}=\frac{\sum N_{i} D_{i}^{3}}{\sum N_{i} D_{i}^{2}}, P=\frac{1}{\bar{D}} \frac{\sum N_{i} D_{i}^{3}\left(\bar{D}-D_{i}\right)}{\sum N_{i} D_{i}^{3}}
$$

where $\bar{D}$ is the median diameter, i.e. the value for which the cumulative undersized volume fraction is equal to $50 \%$, and $N_{i}$ is the total number of particles with diameter $D_{i}$.

Measurements were performed directly after emulsification and over time. In some cases, creamed layers were formed at the top of the recipient under the effect of buoyancy. Before measurements, emulsions were manually shaken to restore homogeneity. Static light scattering data were transformed into droplet size distribution using Mie theory ${ }^{24}$. Before analysis, the emulsions were submitted to a 10 -fold dilution in a $1 \mathrm{wt} . \%$ SDS solution to separate aggregated droplets. The measuring cell was filled with pure water, and a small volume of the sample was introduced under stirring (1 $400 \mathrm{rpm})$.

\subsubsection{Protein concentrations at the interface and in the continuous phase}

The amount of the non-adsorbed proteins in the bulk aqueous phase, was determined using the Bradford assay ${ }^{25}$ based on the formation of a complex between the dye, Brilliant Blue G, and proteins in solution. The protein-dye complex causes a shift in the maximum absorption wavelength of the dye from 465 to $595 \mathrm{~nm}$. The value of the absorbance measured at $595 \mathrm{~nm}$ is proportional to the protein amount. It was assumed that all proteins react with the colored reagent of Bradford, resulting in the same spectral shift of the reagent. The emulsions were centrifuged for 10 to $20 \mathrm{~min}$ at 1000 to $10000 \mathrm{~g}$, g being the earth gravity constant 
(Eppendorf Centrifuge 5430). The oil droplets formed a cream at the top of the vial under the effect of buoyancy. The acceleration rate and the centrifugation time were adjusted for each emulsion in order to obtain a clear subnatant phase, whilst avoiding droplet coalescence in the cream or minimizing it. For the most unstable samples formulated at very low NaCAS content, a thin oil layer was formed at the top the cream which necessarily involved protein desorption. However, the centrifugation time was insufficient for these proteins to diffuse through the thin liquid films in the concentrated cream.

A part of the subnatant phase was collected from the vial by means of a syringe. The protein concentration in this phase, $C_{P r}^{f}$, was determined by the method of Bradford using a UV-vis spectrophotometer (microplate reader Spark 10M TECAN) at a wavelength of 595 nm. Calibration curves were performed with protein (NaCAS or BLG) solutions of known concentrations (from 0.01 to 2 wt.\%) mixed with the Bradford reagent. From $C_{P r}^{f}$ and the surface-averaged diameter, $d_{32}$, the interfacial coverage was determined, by considering the following protein mass balance:

$$
\Gamma=\frac{\left(C_{P r}^{0}-C_{P r}^{f}\right)(1-\phi) d_{32}}{6 \phi}
$$

where $C_{P r}^{0}$ is the initial protein concentration in the aqueous phase, i.e. before emulsification.

\section{Results and discussion}

\subsection{Emulsions stabilized by NaCAS}

\subsubsection{Interfacial coverage}

Emulsions differing in the initial concentration of $\mathrm{NaCAS}$ in the aqueous phase, from 0.1 to 2 wt.\%, were prepared and their droplet size distribution was measured by light-scattering. As can be seen in Figure 1, the droplet size distribution is in the micron or submicron range 
whatever the protein concentration. The distribution shifts towards lower sizes as the protein concentration increases. Interestingly, the polydispersity index, $P$ (indicated in the insert), is in most cases lower than 0.35 , a low value reflecting the formation of emulsions with high degree of monodispersity. This is confirmed by the micrograph of Figure 1, where drops with a quite uniform size are visible. The oil droplets are perfectly well dispersed in the aqueous phase and submitted to Brownian motion.
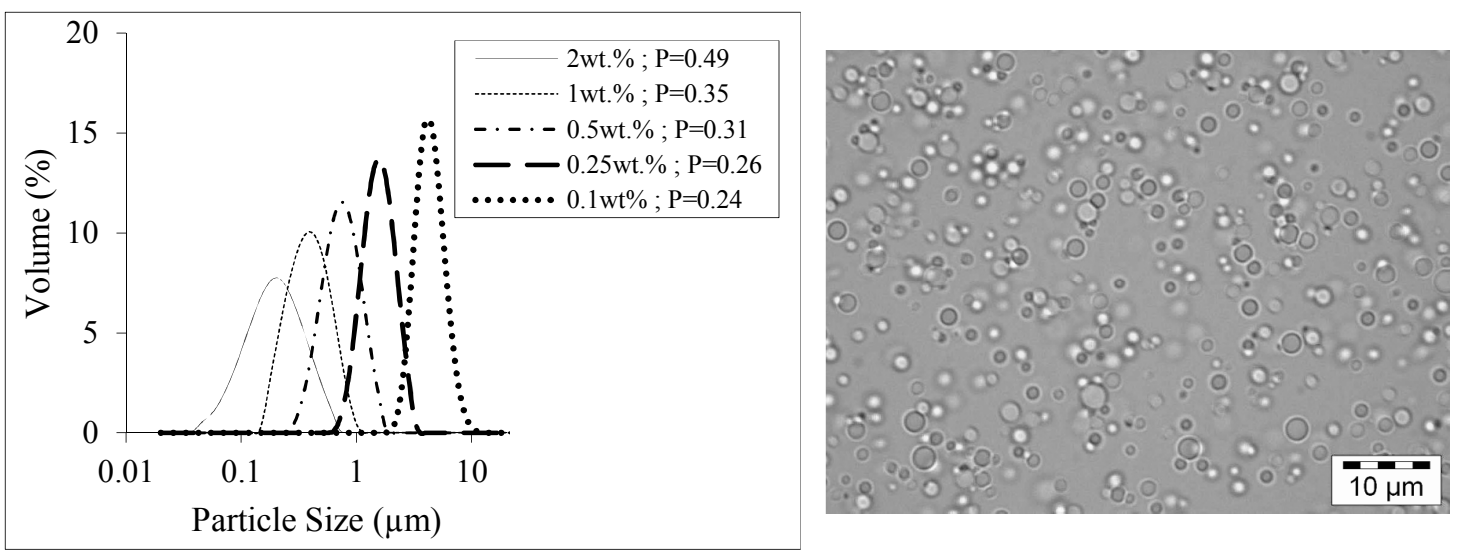

Figure 1. Left: Droplet size distribution as a function of the initial concentration of NaCAS in the aqueous phase, $C_{P r}^{0}$, expressed in weight percent of the aqueous phase. Measurements were performed right after emulsification. Right: Characteristic micrograph of the emulsion obtained with 0.25 wt. $\%$ NaCAS.

The protein concentrations explored here are rather low and it is likely that the shear applied by the microfluidizer is able to generate much more interfacial area than what proteins can cover. Since proteins are in general irreversibly adsorbed, conditions are thus met for limited coalescence to be operative: when the agitation is stopped, droplets recombine until the degree of interfacial coverage becomes sufficient to stabilize them against further coalescence, at least at short times. One of the main features of this regime is its ability to generate narrow droplet size distributions ${ }^{21,22,26}$. Assuming that the coalescence probability 
between two drops is simply proportional to their individual uncovered surface fraction, Monte Carlo simulations performed by Whitesides and Ross $(1995)^{22}$ predict droplet size distributions that are much narrower than those resulting from unlimited coalescence. One interesting conclusion from their numerical calculations is that the final droplet size distribution is insensitive to the agitation conditions and to the details of the initial droplet size distribution (uniformity, interfacial coverage) within fairly wide limits. The degree of monodispersity achieved in our emulsions gives a hint that they result from a limited coalescence process.

The amount of non-adsorbed (free) protein in the continuous phase was measured just after emulsification from the Bradford assay. It was systematically found below $4 \%$ of the initial protein content, indicating that proteins were almost fully adsorbed at the oil-water interface. The emulsification time and the number of passes in the homogenizing chamber were thus sufficient to ensure almost full mobilization of the proteins at the interfaces. Eq. 1 (identically Eq. 3 with $C_{P r}^{f} \approx 0$ ) can be rewritten so as to make the droplets interfacial area, A, apparent:

$$
A=\frac{6 V_{d}}{d_{32}}=\frac{m_{a}}{\Gamma} \approx \frac{C_{P r}^{0} V_{c}}{\Gamma}
$$

where $V_{d}$ is the volume of the dispersed phase, $V_{c}$ is the volume of the continuous phase and $m_{a}$ is the mass of adsorbed proteins. Assuming that the interfacial coverage adopts a unique value at the end of the limited coalescence process, $\Gamma$ can be determined from the slope of the curve representing the evolution of the total surface area of the droplets, $A$, as a function of $m_{a}$. Figure 2 shows the corresponding plot deriving from the data presented in Figure 1 . The linearity confirms our hypothesis about the existence of a unique interfacial coverage right after the emulsification process. From the slope of the plot, we deduce $\Gamma=1.8 \pm 0.1 \mathrm{mg} \cdot \mathrm{m}^{-2}$, a value comparable to that generally reported for this protein ${ }^{2}$. Figure 2 can be regarded as a master curve enabling the mean droplet size to be predicted with great accuracy. Indeed, in 
the limited coalescence regime (low protein content), the mean droplet size is only governed by a critical value of the surface coverage, characteristic of the emulsifier, and is not supposed to depend on the hydrodynamic conditions ${ }^{10}$.

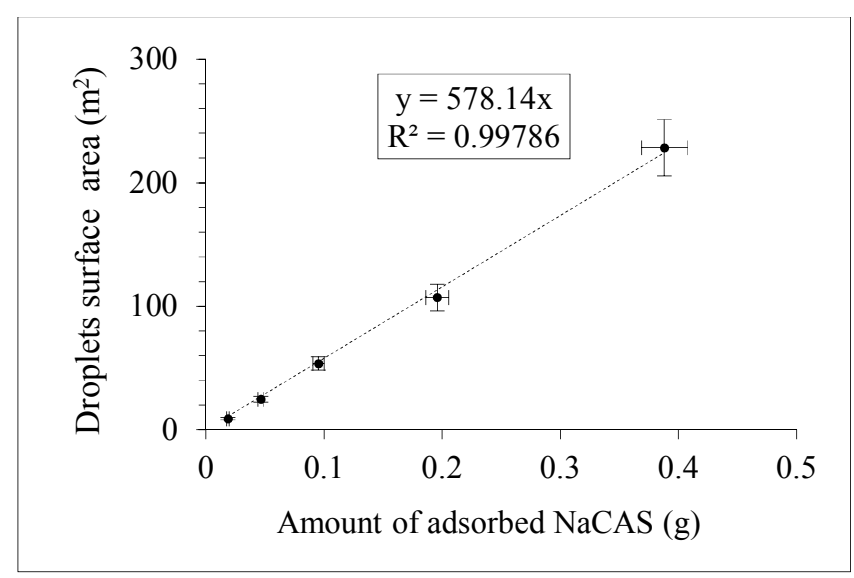

Figure 2. Droplet surface area as a function of the amount of NaCAS adsorbed for emulsions with $20 \mathrm{wt} . \%$ oil; the total emulsion mass is $25 \mathrm{~g}$. Measurements were performed right after emulsification.

\subsubsection{Emulsion stability}

The kinetic stability of the emulsions was assessed by monitoring the time-dependency of their droplet size distribution under quiescent storage conditions. All data regarding the evolution of the size distribution for 30 days are gathered in Table S1 (Supporting Information). Measurements were interrupted once a thin oil layer was noticed at the top of the emulsion vials. The 2 finest emulsions obtained with $C_{P r}^{0}=1$ and 2 wt.\% remained homogenous and their droplet size distribution did not evolve during the whole storage period. In contrast, emulsions with $C_{P r}^{0}=0.1,0.25$ and $0.5 \mathrm{wt} . \%$ were subjected to changes in their droplet size distribution after a relatively short period of time (20 $\min$ for $C_{P r}^{0}=0.1 \mathrm{wt} . \%$, 1 hour for $C_{P r}^{0}=0.25$ wt. $\%$ and 7 days for 0.5 wt. $\%$ ). For the sake of illustration, we shall 
focus on the results obtained for the emulsion initially containing $0.25 \mathrm{wt} . \% \mathrm{NaCAS}$ in the aqueous phase. Because of their large droplet size $\left(\mathrm{d}_{32}=1.56 \mu \mathrm{m}\right.$ at $\left.t_{0}\right)$ and of their large density mismatch relative to the aqueous phase $\left(\Delta \rho=0.227 \mathrm{~g} . \mathrm{cm}^{-3}\right)$, droplets were prone to fast creaming. Coalescence was observed after $1 \mathrm{~h}$ as evidenced in Figure 3 where the distribution significantly widens towards larger droplet sizes (equivalently, the polydispersity index increases). In addition, a thin oil layer was clearly visible at the top of the sample after 12 hours. These observations clearly evidence the fact that the protein interfacial coverage after emulsification was insufficient to ensure longstanding stabilization. Creaming enhances the contacts between droplets so that unlimited coalescence is favored. Weak stabilization has already been reported in emulsions based on NaCAS caseinate at low concentration ${ }^{27}$.

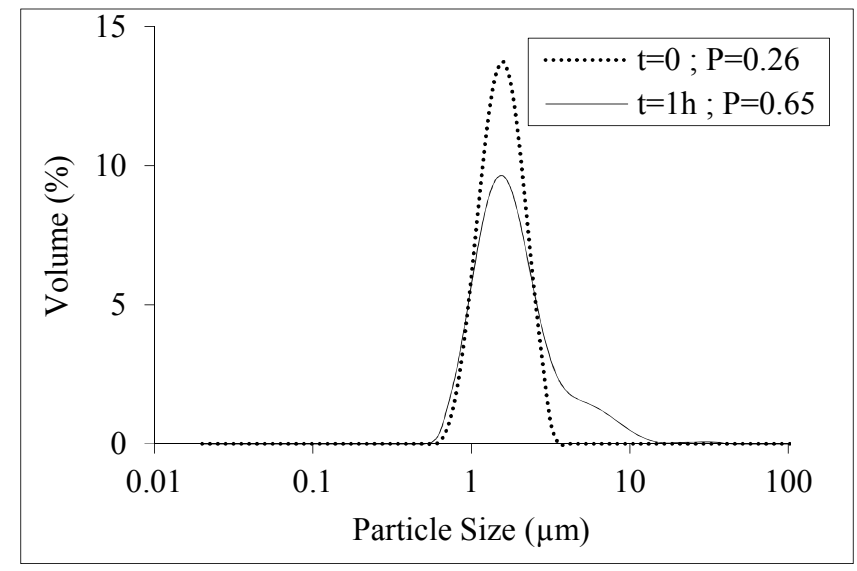

Figure 3. Evolution of the droplet size distribution in an emulsion prepared with 0.25 wt.\% $\mathrm{NaCAS}$ in the aqueous phase.

\subsubsection{Impact of protein addition in the continuous phase}

To prevent emulsion destabilization by promoting further adsorption of emulsifier, we incorporated free proteins in the aqueous phase. Different amounts of $\mathrm{NaCAS}$, from 0 to 2 wt.\% with respect to the aqueous phase, were added to the emulsions right after the homogenization process by means of a 14 wt.\% NaCAS, $0.01 \mathrm{~mol}^{-\mathrm{L}^{-1}} \mathrm{NaN}_{3}$ solution. Owing to its large protein concentration, only a small amount of this solution had to be introduced so 
that the final droplet fraction was not significantly modified (it varied from 20 to 17.5 wt.\%). Figure 4 shows the droplet size distributions of an emulsion initially fabricated with 0.25 wt. $\%$ proteins, containing additional proteins, measured after $1 \mathrm{~h}$ to 1 -month storage. The shoulder or the mode present in the right part of the distributions reflects the formation of large drops induced by coalescence (Figure 4a). The shoulder and/or the mode becomes less pronounced as the additional protein concentration increases (Figure $4 \mathrm{~b}$ ). Beyond $0.5 \mathrm{wt} . \%$ of added proteins, there is no clear evidence for droplet coalescence after 48h (Figure 4c): the droplet size distribution remains almost identical to the initial one. The stability gain was further confirmed by considering an emulsion with 1 and 2 wt. $\%$ of added protein: in this case, the emulsion did not evolve significantly, even after 30 days of storage (Figure $4 \mathrm{~d}$ and e). In Figure 5, we report a stability map after 1 month-storage expressed using 2 variables: the initial protein concentration, $C_{P r}^{0}$, and the amount of additional protein, $C_{P r}^{a d d}$, incorporated in the aqueous phase after emulsification. Filled symbols represent samples whose average droplet size varied by less than $10 \%$, whereas open symbols correspond to systems that coalesced to a great extent (shoulder in the size distribution or apparent oil layer at top of the recipient). The dotted line is a guide for the eyes that reflects the transition between kinetically stable and unstable emulsions. The amount of additional protein required to stabilize emulsions decreases as $C_{P r}^{0}$ increases. Up to a critical value of $C_{P r}^{0}$, between 0.5 and $1 \mathrm{wt} . \%$, it is not even necessary to incorporate additional proteins. Large droplets obtained at lowest concentrations exhibited fast coalescence essentially because of the significant creaming rate that tended to concentrate them. Fast diffusion towards the interfaces and adsorption of additional proteins was required to stabilize the emulsions before the cream was actually formed and this was achieved by increasing $C_{P r}^{a d d}$ up to a sufficient level. 


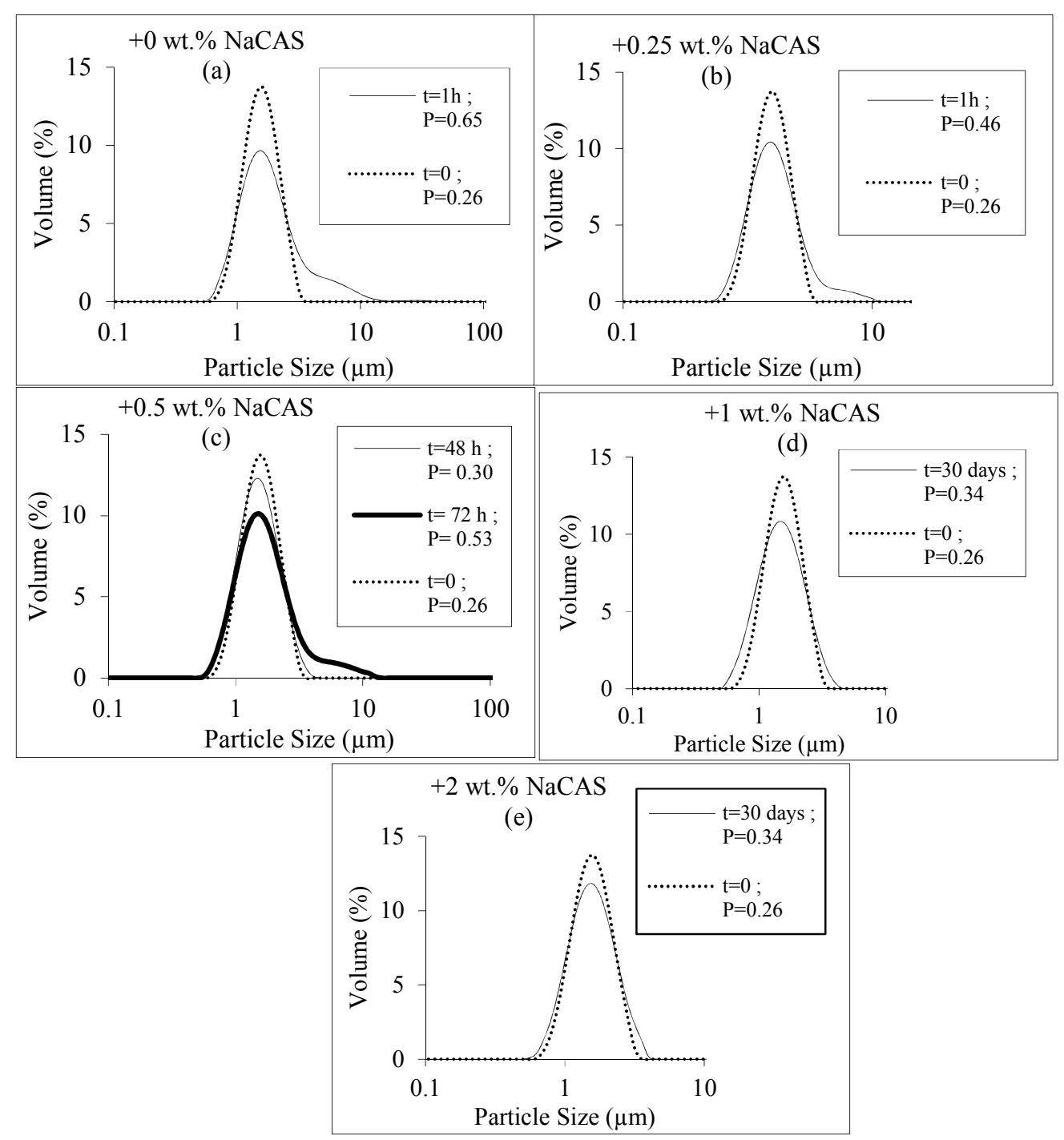

Figure 4. Kinetic evolution of the droplet size distribution measured after adding variable amounts of additional proteins (expressed with respect to the aqueous phase) in an emulsion initially fabricated with 0.25 wt. $\%$ NaCAS. 


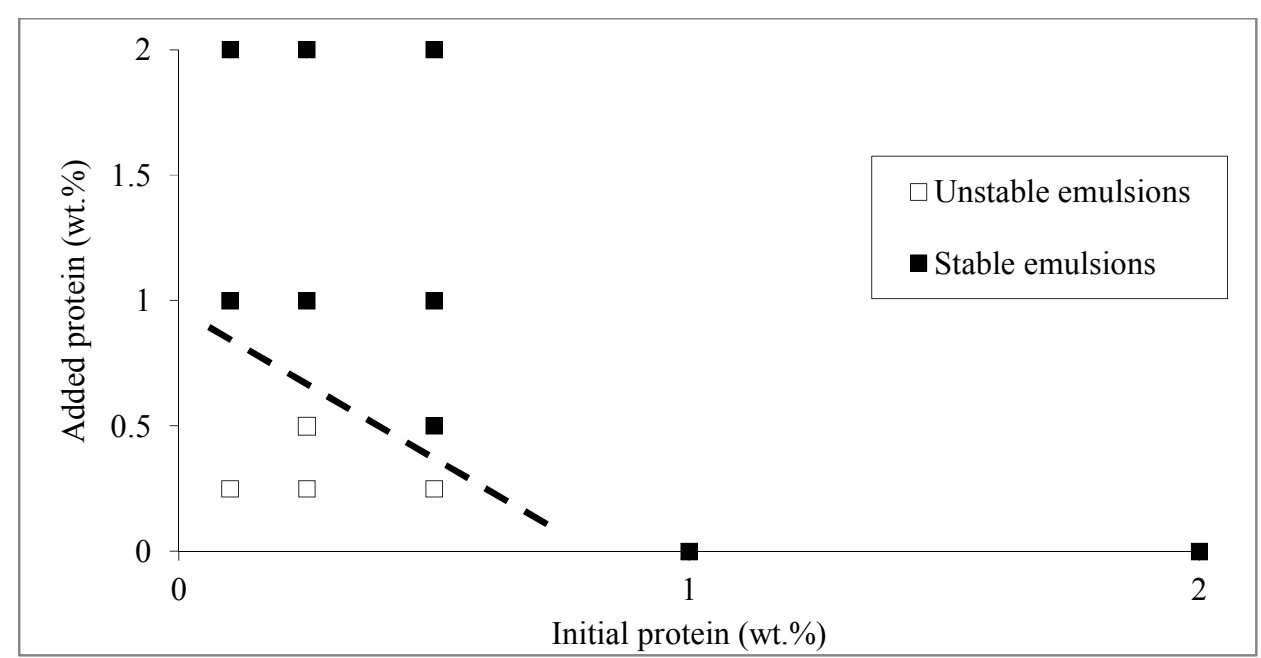

Figure 5. State of the emulsions after 1-month storage. The dotted line is a guide for the eyes reflecting the transition between kinetically stable and unstable emulsions in the diagram.

The same trend was observed when the emulsion stability was evaluated under accelerated ageing conditions. All emulsions were submitted to a centrifugation step at 20000 g for $15 \mathrm{~min}$. As shown in Figure 6, a concentrated cream made of densely packed droplets was formed in the centrifugation tubes. Considering the thickness of the cream, it can be stated that the average droplet fraction exceeds 90 vol.\%. Above this cream, another phase, less turbid, was observed. It consists of an oil layer resulting from droplets coalescence. The thickness of this layer decreases when the amount of added NaCAS increases. For the emulsion supplemented with 2 wt.\% protein, the oil layer becomes very thin and hardly discernable. 


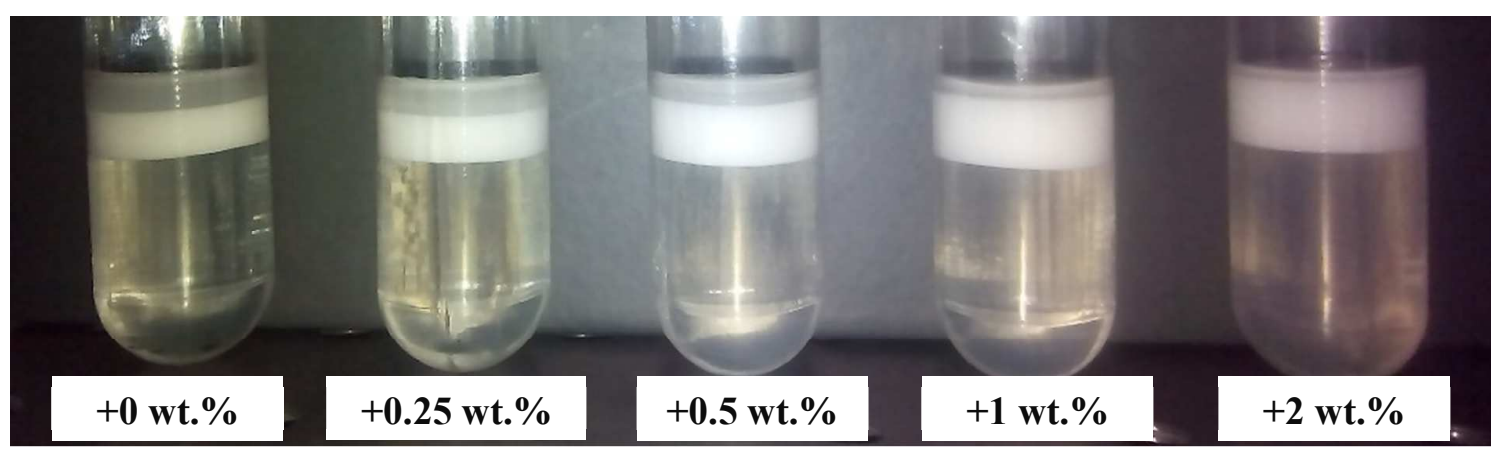

Figure 6. Influence of protein addition on the stability under centrifugation (15 min/20 $000 \mathrm{~g})$

To verify that the stability gain was due to the adsorption of proteins incorporated after the emulsification process, we measured the residual concentration of proteins in the aqueous phase after $20 \mathrm{~h}$ of storage. The experiment was performed with an emulsion fabricated at $C_{P r}^{0}=1$ wt. $\%$, whose initial mean droplet diameter was $d_{32}=0.36 \mu \mathrm{m}$. In this case, the total interfacial area, $A$, was large enough to produce a significant change in the amount of free protein after interfacial adsorption. The mass balance made it possible to determine the variation of total interfacial coverage, $\Gamma$, with sufficient accuracy. In Figure 7, we report the variation of $\Gamma$ as a function the amount of added proteins which ranged from 0 to $4.2 \mathrm{wt} . \%$. $\Gamma$ significantly increases upon addition of proteins in the continuous phase and reaches $4.9 \pm 0.2$ $\mathrm{mg} . \mathrm{m}^{-2}$ at 4.2 wt. $\%$ of added protein. The latter value of $\Gamma$ is well above the value for a dense protein monolayer, which is expected to be close to $2 \mathrm{mg} \cdot \mathrm{m}^{-2}$. The same experiment was carried out with emulsions fabricated at $C_{P r}^{0}$ values ranging from 0.1 to $1 \mathrm{wt} . \%$, differing in their initial droplet size. Additional proteins were incorporated at $2 \mathrm{wt} . \%$ in the aqueous phase. The proportion of adsorbed proteins varied linearly with the interfacial area, as can be seen in Figure S2. This result proves that the interfacial coverage increases similarly irrespective of the mean droplet size. The results reported in Figure 7, obtained for a specific mean droplet size, can thus be generalized. The excess of protein adsorption most probably 
reflects the formation of a multilayer containing adsorbed protein aggregates, like casein micelles. Multilayer formation has been reported for whey proteins by for instance Sunder, Scherze, \& Muschiolik (2001) ${ }^{28}$ and by Tcholakova, Denkov, Ivanov, \& Campbell (2002) ${ }^{10}$.

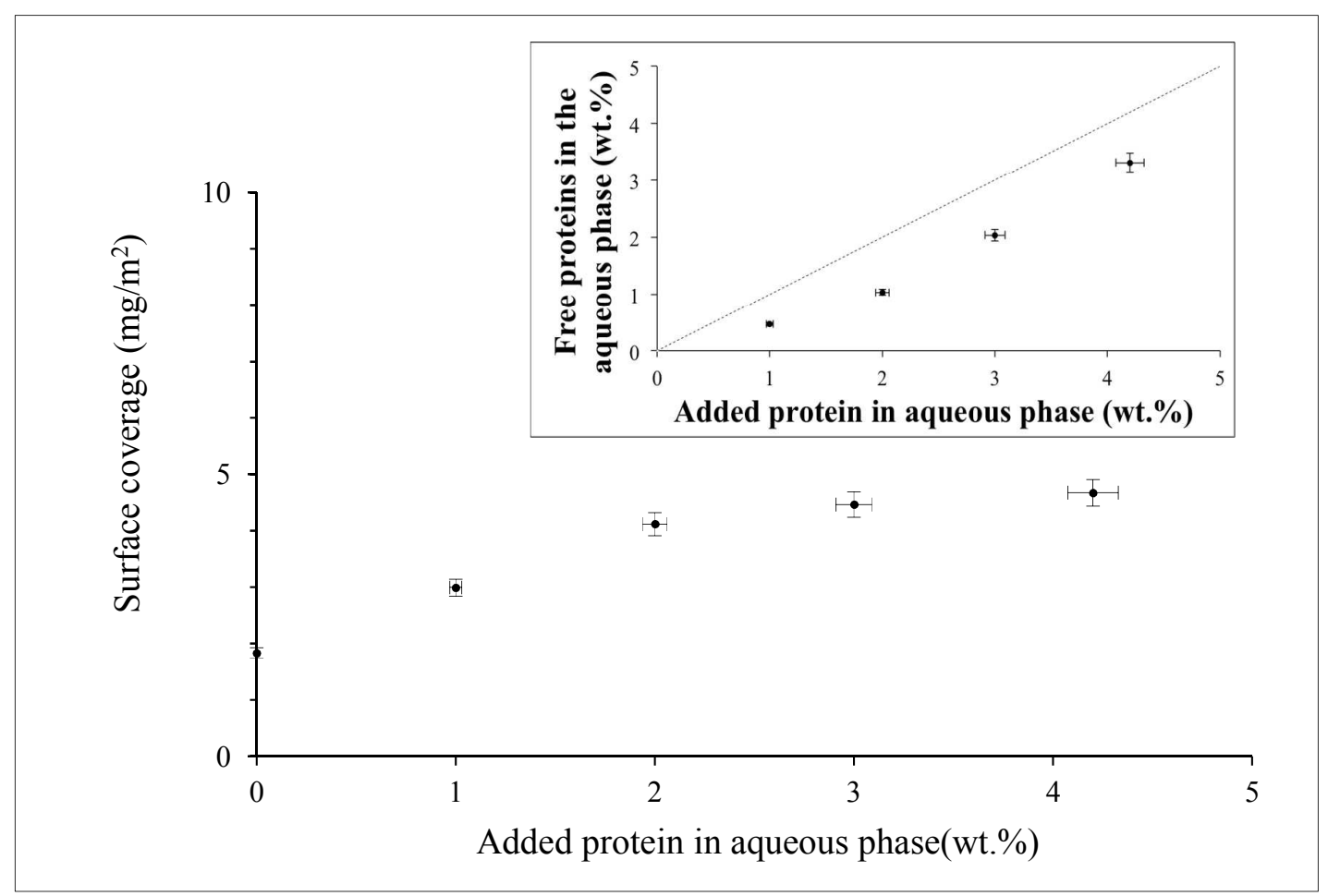

Figure 7. Evolution of the surface coverage as a function of added protein (wt.\% expressed with respect to the aqueous phase) for an emulsion fabricated with 1 wt. $\%$ NaCAS.

A significant fraction of additional NaCAS remained free in a non-adsorbed state. This can be clearly seen in the insert of Figure 7, where we plot the variation of the concentration of free proteins in the aqueous phase as a function of the total amount of added proteins. Free emulsifiers may have huge consequences for emulsion stability. Indeed, the interfaces of the droplets are stretched and pressed one against each other during Brownian collisions. The interfacial surfactant density is transiently lowered resulting in a less efficient protection against coalescence. Surfactant molecules that diffuse from the bulk to the surface may dampen interfacial density fluctuations in the thin liquid films. Since the rate of diffusion 
increases with surfactant concentration, coalescence would be slowed down. To check whether the stability gain can be ascribed to multilayer formation or to free proteins in the aqueous phase, we rinsed with electrolyte solution $\left(0.01\right.$ mol. $\left.\mathrm{L}^{-1} \mathrm{NaN}_{3}\right)$ the cream formed from an emulsion prepared with 0.5 wt.\% NaCAS and supplemented with 2 wt.\% protein. This emulsion was first stored for $20 \mathrm{~h}$ at $25{ }^{\circ} \mathrm{C}$. Then, it was diluted 2 times with a 0.01 mol.L $\mathrm{L}^{-1} \mathrm{NaN}_{3}$ solution and centrifuged at $1000 \mathrm{~g}$ for $1 \mathrm{~h}$ to separate the droplets from the aqueous phase. Afterward, the aqueous phase was removed using a syringe, and the same volume of 0.01 mol. $\mathrm{L}^{-1} \mathrm{NaN}_{3}$ solution was gently introduced below the cream. The sample was gently shaken by hand until the emulsion drops were completely dispersed. The centrifugation step was repeated once again and the cream was diluted with a $\mathrm{NaN}_{3}$ solution to set the oil fraction at $20 \mathrm{wt} . \%$. After the rinsing process, the free protein amount in the aqueous phase measured by the Bradford assay was of the order of 0.025 wt.\%. The droplet size distribution in the rinsed emulsion was found to be the same as that of the original emulsion.

Figure 8 shows that removal of free proteins did not have any noticeable influence on the stability of the emulsion supplemented with NaCAS: it remained stable over a 30-day period with an almost unchanged $d_{32}$ value of $0.8 \mu \mathrm{m}$. In contrast and as expected, the nonsupplemented emulsion underwent coalescence that was apparent in the droplet size distribution after 15 days. These observations suggest that at least a fraction of the added proteins irreversibly adsorbed at the oil/water interface. The surface coverage increases after protein addition ensuring emulsion stability over 30 days, even if free proteins are removed. 
The stability of emulsions submitted to centrifugation $(20000 \mathrm{~g}$ for $15 \mathrm{~min})$ was also evaluated. The thickness of the oil layer formed at the top of the sample can be considered as a reliable indicator of the ability of emulsions to withstand coalescence upon concentration of the droplets. Figure 9 compares the macroscopic state of 3 emulsions initially prepared with 0.5 wt. $\%$ NaCAS. Without protein supplementation (emulsion 1), massive coalescence occurs and is revealed by a thick oil layer. Conversely, the oil layer is quite thin for the emulsion supplemented with 2 wt.\% NaCAS and rinsed (emulsion 2), and almost invisible for the supplemented and unrinsed emulsion (emulsion 3). In this case, the removal of free proteins has a moderate but visible impact on the stability. These observations confirm the substantial stability gain provided by protein supplementation while revealing a supplementary stabilizing effect of free proteins under accelerated ageing conditions. 


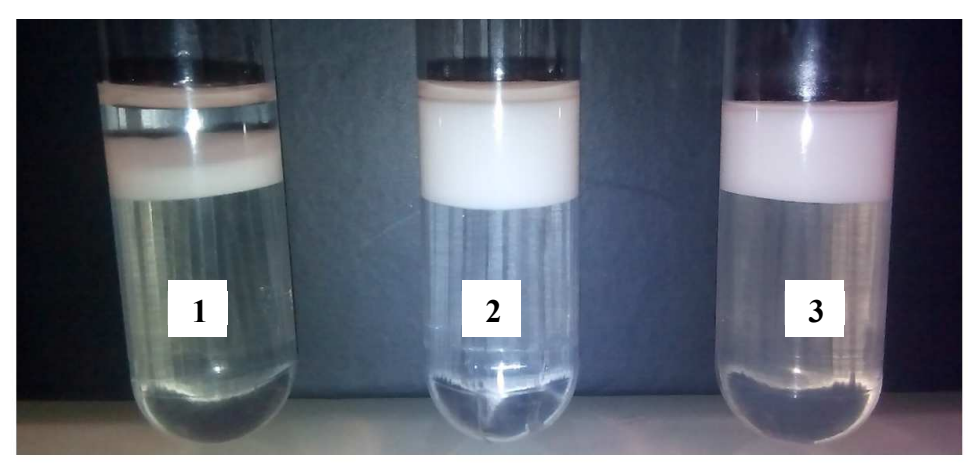

Figure 9. Stability under centrifugation for an emulsion initially prepared with 0.5 wt.\% NaCAS. (1) Not supplemented; (2) supplemented with 2 wt.\% NaCAS and rinsed; (3) supplemented with 2 wt.\% NaCAS, unrinsed.

\subsubsection{Impact of ionic strength on NaCAS adsorption}

In section 3.1.3, we showed that for the emulsion initially fabricated with $0.25 \mathrm{wt} . \%$ proteins, addition of 1 wt. $\%$ NaCAS stabilized it over a 1 month-period, whereas coalescence was observed after adding $0.25 \mathrm{wt} . \%$ protein (Figure 4 ). In the latter case, it can be hypothesized that the increment in interfacial coverage was insufficient and/or the adsorption rate was too slow. It is generally observed that the adsorption rate of charged species like proteins is first controlled by diffusion on the almost bare interface and then by the electrostatic energy barrier once the interfacial coverage becomes sufficiently high. In this limit, increasing the ionic strength has generally the effect of screening the electrostatic repulsion, thus reducing the energy barrier for adsorption. In order to increase the adsorption rate and/or the interfacial coverage, we simultaneously added $\mathrm{NaCl}$ and $\mathrm{NaCAS}$. Three levels of $\mathrm{NaCl}$ addition were probed, together with 0.25 wt.\% NaCAS supplementation: 0 (no $\mathrm{NaCl}$ addition); $0.01 \mathrm{~mol} . \mathrm{L}^{-1}$ and $0.025 \mathrm{~mol} . \mathrm{L}^{-1}$. In the absence of $\mathrm{NaCl}$, coalescence was detected in the droplet size distribution after a $1 \mathrm{~h}$ storage period (see Figure 4b). With 0.01 mol. $\mathrm{L}^{-1} \mathrm{NaCl}$, the size distribution after 30 days widened towards larger sizes $(P=0.51)$, as evidenced by Figure $10 \mathrm{a}$. Increasing $\mathrm{NaCl}$ concentration 
up the 0.025 mol. $\mathrm{L}^{-1}$ clearly improved emulsion stability, whose size distribution remained almost invariant over the explored time period, although the droplets were flocculated (Figure 10b). These results show that increasing the ionic strength via monovalent salts like $\mathrm{NaCl}$ allows reducing the amount of protein to be added to ensure kinetic stabilization.
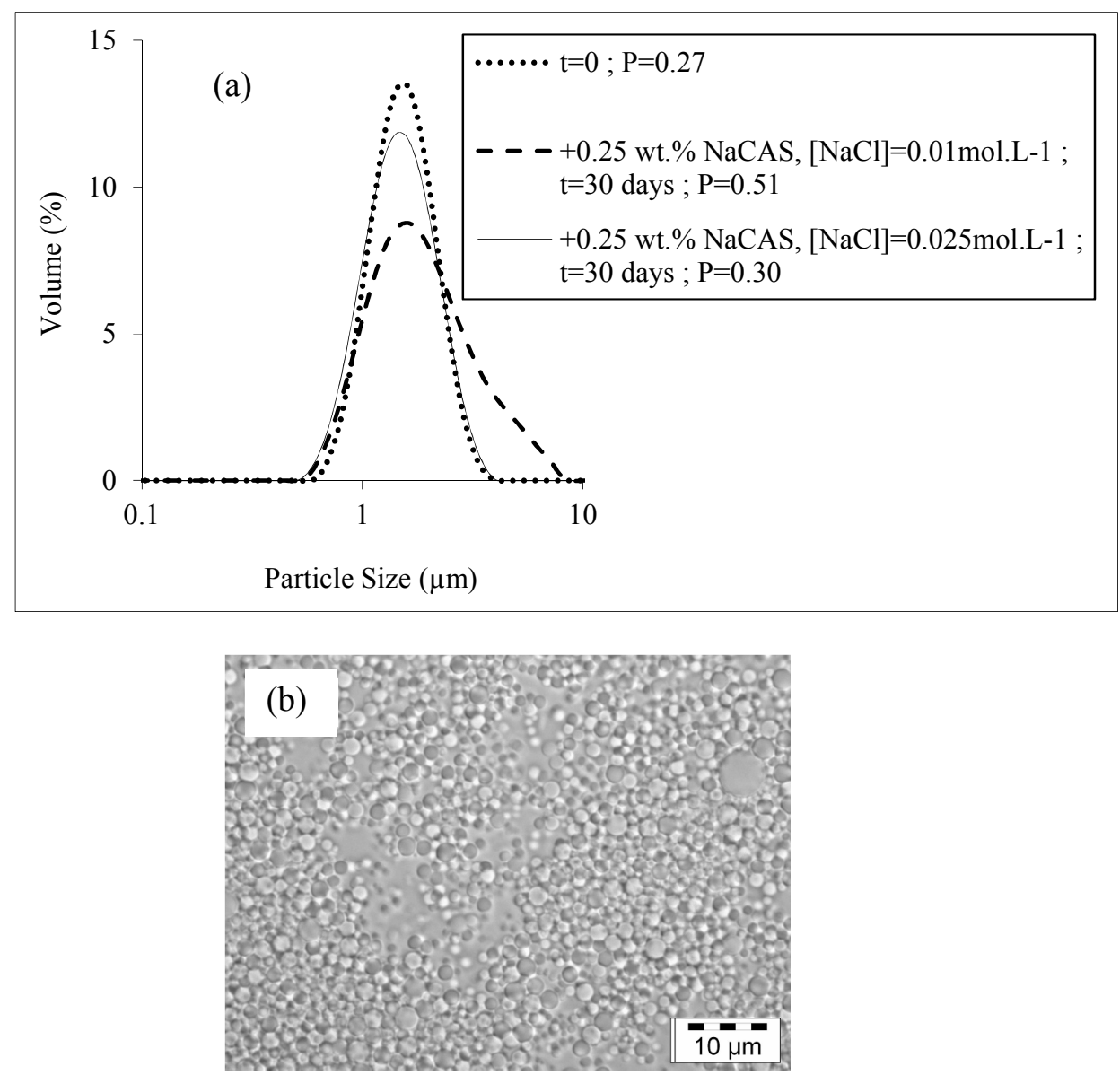

Figure 10. (a) Evolution of the droplet size distribution of an emulsion initially prepared with 0.25 wt. $\%$ NaCAS, supplemented with 0.25 wt.\% protein and $\mathrm{NaCl}$ at various concentrations. (b) Characteristic micrograph of the emulsion supplemented with $0.025 \mathrm{~mol} . \mathrm{L}^{-1} \mathrm{NaCl}$. 


\subsubsection{Alternative methods to stabilize NaCAS emulsions}

Two alternative strategies were probed to stabilize emulsions initially formulated at low NaCAS content $(0.25$ wt.\%): acidification of the aqueous phase $(\mathrm{pH}=4.6$ and 1.8$)$ and addition of calcium ions $\left(0.01 \mathrm{~mol} . \mathrm{L}^{-1}\right)$. A common feature of both strategies is their propensity to produce protein aggregation ${ }^{29-32}$. Since almost all proteins are adsorbed (see section 3.1.1), protein aggregation should result in more viscoelastic and tangentially immobile interfacial layers (gel-like network) that should better protect emulsions against coalescence. Dickinson and Davies $(1999)^{33}$ have explored the effect of ionic calcium on the stability of caseinate emulsions of controlled droplet size and protein, fabricated via high pressure homogenization. They found that the behavior is sensitive to whether the calcium salt is introduced before or after homogenization. In their study, the variations in the size distributions reflected both coalescence and aggregation phenomena.

The kinetic evolution of the droplet size distributions for emulsions supplemented with $\mathrm{Ca}^{2+}$ ions is reported in Figure $\mathrm{S} 3$. When $\mathrm{CaCl}_{2}$ was added after emulsification, the droplet size distribution underwent a sudden shift: the mean diameter, $d_{32}$, increased from $1.5 \mu \mathrm{m}$ to 2 $\mu \mathrm{m}$ and the distribution remained narrow $(P=0.35)$. Afterwards, the emulsion remained kinetically stable for at least one month (Figure S3.Ia), although the droplets were aggregated and exhibited fast creaming (Figure S3.IIa). The observed transition from short to long-range kinetic stability was due to an increase in the interfacial coverage induced by limited coalescence. Indeed, we checked that proteins remained adsorbed after $\mathrm{CaCl}_{2}$ addition: within experimental precision, no increment of the NaCAS concentration was detected in the aqueous phase. The shift in the droplet size distribution was due to supplementary coalescence events that reduced the interfacial area until a point that a denser packing of the proteins at the interface was reached. According to Eq. 1, the surface coverage, $\Gamma$, became equal to $2.3 \pm 0.1 \mathrm{mg} \cdot \mathrm{m}^{-2}$, a value substantially higher than that measured in emulsions without 
calcium ions (1.8 $\pm 0.1 \mathrm{mg} \cdot \mathrm{m}^{-2}$, see section 3.1.1). Srinivasan, Singh, \& Munro (1996) ${ }^{32}$ and Ye $\&$ Singh $(2001)^{34}$ identically observed that the addition of calcium chloride resulted in higher interfacial coverages. The effect of calcium ions on the properties of NaCAS emulsions is a consequence of the anionic phosphoseryl residues clustering in the casein molecules ${ }^{8}$. Calcium ions reduce intermolecular electrostatic repulsions, while hydrophobic interactions produce the aggregation of the molecules ${ }^{8,33,35}$.

We also fabricated an emulsion containing 0.01 mol. $\mathrm{L}^{-1}$ of calcium ions in the continuous phase before microfluidization. The size distribution was identical to that of the emulsion supplemented with calcium after microfluidization and it did not show any evolution for 30 days either (Figure S3.Ib). Thus, addition of calcium ions ensures efficient stabilization against coalescence, whether incorporated before or after emulsification.

The influence of $\mathrm{pH}$ in emulsions with sodium caseinate was evaluated by Perrechi \& Cunha $(2010)^{36}$ who observed an increase in the stability of emulsions with a pH between 2.7 and 6.6, with the exception of a $\mathrm{pH}$ close to the isoelectric point $(4.6<\mathrm{pI}<5)$. Following this seminal work, we explored the behavior of our emulsions in the vicinity of the isoelectric point $(\mathrm{pH}=4.6)$, and far from it, in highly acidic conditions $(\mathrm{pH}=1.8)$. The two modes of incorporation, before and after emulsification, were probed and gave similar results. The evolution of the droplet size distributions at $\mathrm{pH}=4.6$ are given in Figure S3.Ic. This emulsion was rapidly destabilized. In contrast, the emulsion at $\mathrm{pH}=1.8$ was stable against coalescence for at least one month (Figure S3.Id and e). When the acidification was performed after emulsification, the droplet underwent flocculation (Figure S3.IIb1 and b2) but their size distribution was almost identical to that of the emulsion they derived from (Figure S3.Id). 
Alayón-Marichal $(2014)^{37}$ estimated the number of amino-acids of NaCAS located at an interface for different $\mathrm{pH}$ values. For the estimation, it was supposed that, for a specific $\mathrm{pH}$, the amino-acids without charge (hydrophobic groups) were at the interface and the aminoacids with charge (hydrophilic groups) were into the aqueous phase. At $\mathrm{pH}=1.9$, it was predicted that casein molecules have enhanced hydrophobicity with the highest ratio of amino-acids located at the interface. As a result, a large proportion of the protein molecules avoid the aqueous phase by altering their conformation in an attempt to be located at the interface while the hydrophilic part is immersed into the aqueous phase. The net positive charge on the proteins creates an electrostatic repulsion. A large area at the interface is occupied by the sodium caseinate proteins because of their high hydrophobic character and the electrostatic repulsion between the protein molecules. We checked that protein desorption did not occur upon acidification. Considering the data of Alayón-Marichal $(2014)^{37}$, this situation is likely to produce high compaction of the monolayer and thus high interfacial elasticity. Because of the short center-to-center distance and the intrinsic repulsion between proteins, hydrophilic moieties cannot expand laterally. However, they may potentially expand along the normal to the interface and the monolayer thickness is thus expected to increase. This could explain why emulsions are remarkably stable against coalescence at $\mathrm{pH}=1.8$.

\subsection{Emulsions stabilized by BLG}

\subsubsection{Interfacial coverage}

We now consider the behavior of emulsions stabilized by BLG. To fabricate them, the protein content in the aqueous phase was varied from 0.25 to $2 \mathrm{wt} . \%$. Again, the droplet size distributions were quite narrow, as revealed by the low values of the polydispersity index in Figure $11(0.35<P<0.50)$ and by the micrographs of Figure 12. Emulsions based on BLG 
were always aggregated. Unlike NaCAS, BLG proteins were not fully adsorbed after the emulsification process. Irrespective of the initial content, the percentage of free proteins in the aqueous phase was significant, about $12 \%$, and this unadsorbed fraction remained constant over time (even after 4 days of storage). In Figure 12, we plot the evolution of the interfacial area versus the mass of adsorbed BLG. The linear variation confirms that the emulsions can be characterized by a unique interfacial coverage in the explored BLG concentration range. From the slope, we obtain $\Gamma=1.1 \pm 0.1 \mathrm{mg} \cdot \mathrm{m}^{-2}$, a value which is in accord with previous studies $^{38}$.
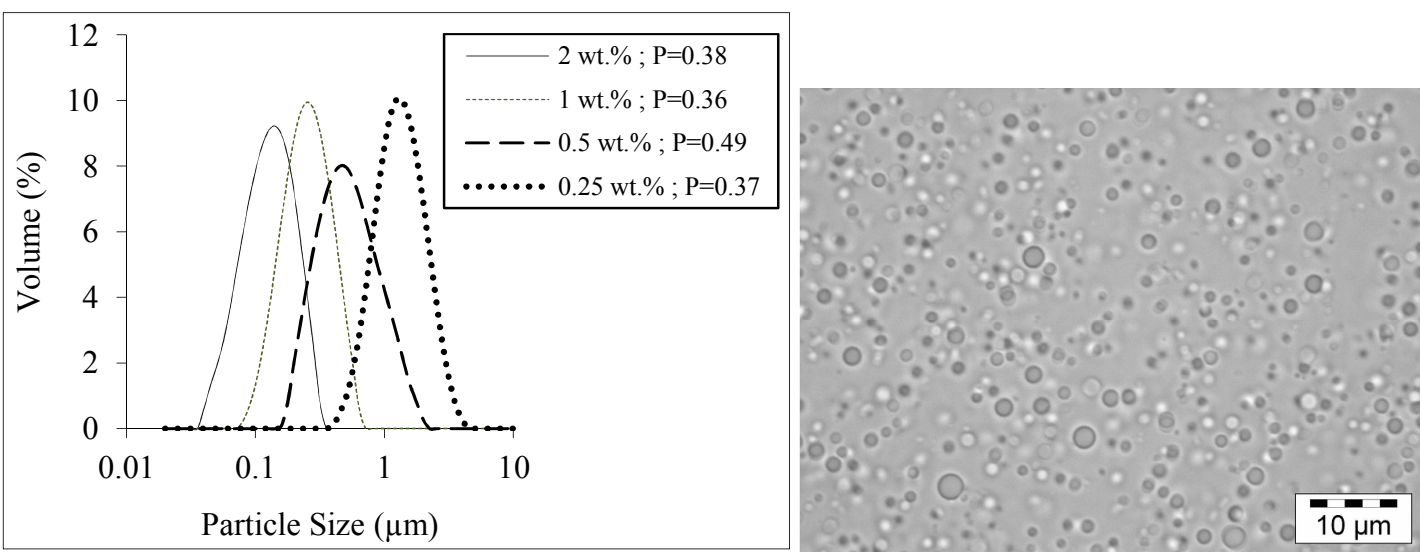

Figure 11. Left: droplet size distribution as a function of initial protein (BLG) in the aqueous phase. Measurements were performed right after emulsification. Right: characteristic micrograph of the emulsion stabilized with $0.25 \mathrm{wt} . \%$ BLG. The emulsion was diluted in 1 wt.\% SDS solution to disaggregate the droplets and facilitate the observation. 


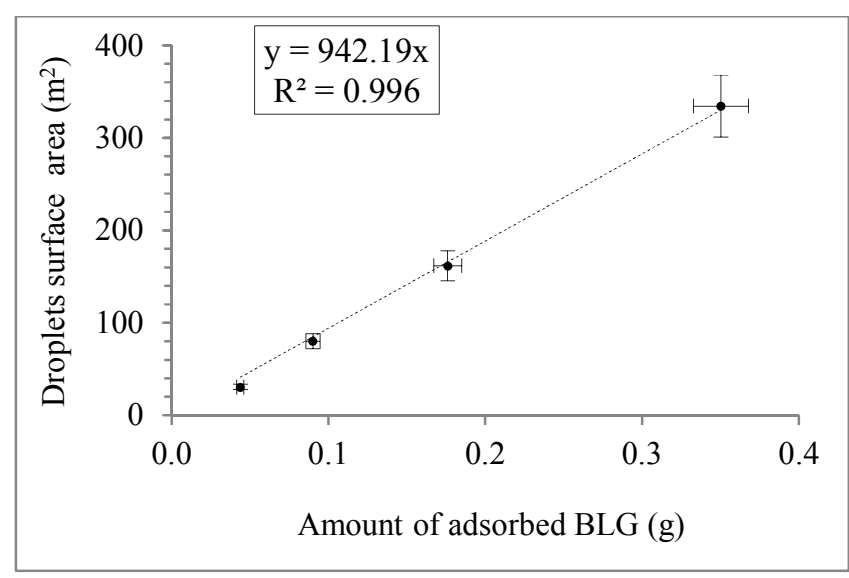

Figure 12. Droplet surface area as a function of the amount of BLG adsorbed for emulsions with $20 \mathrm{wt} . \%$ oil; the total emulsion mass is $25 \mathrm{~g}$. Measurements were performed right after emulsification.

\subsubsection{Emulsion stability}

The stability of BLG-stabilized emulsions was followed for 30 days and no significant evolution of the droplet size was noticed over this storage period (see Figure S4). In this case, further protein supplementation was therefore not necessary to ensure kinetic stability. These results emphasize fundamental differences between NaCAS and BLG, regarding their interfacial behavior. It is well established that the structure of the adsorbed protein film and the adsorption kinetics are influenced by the stability of the native state $^{39}$. For globular proteins like BLG, the dynamics of adsorption and conformation rearrangement in the interfacial region are extremely slow. The interfacial tension and interfacial rheological properties continue to evolve over time scales of days ${ }^{39-42}$. Comparatively, caseins exhibit must faster adsorption kinetics owing to their soft flexible structure ${ }^{12}$. This could explain why, under similar emulsification condition, we observed almost full adsorption of NaCAS while the adsorption of BLG was only partial. 
Using interfacial shear and dilatational rheology, Freer, Yim, Fuller, \& Radke (2004) ${ }^{12}$ compared the kinetics of network formation at the hexadecane/water interface of a globular protein, lysozyme, and of a disordered protein, $\beta$-casein. For lysozyme, the shear moduli grew with interface age indicating a transition from fluid-like behavior at early times to solid-like behavior. Conversely, the interfacial shear moduli of $\beta$-casein changed very little with interface age. The authors argued that the strong protein intramolecular interactions that stabilize the native conformation of globular proteins act as kinetic barriers to conformational change and later generate strong intermolecular interactions upon partial unfolding at the interface. The ability of proteins to form an interfacial membrane that is resistant to rupture plays an important role in stabilizing the droplets against coalescence during long-term storage $^{10,11,43}$. In that respect, globular proteins are expected to provide better stabilization against coalescence than NaCAS.

\section{Summary and Conclusions}

In this paper, we exploited the limited coalescence regime that is operative at low protein concentrations to fabricate $\mathrm{O} / \mathrm{W}$ emulsions based on $\mathrm{NaCAS}$ and $\mathrm{BLG}$, using a microfluidizer. In this regime, the mean droplet size was controlled by a unique surface coverage and consequently the total interfacial area was simply proportional to the amount of protein. Both proteins have in common to adsorb irreversibly at an oil/water interface, allowing limited coalescence to take place and highly monodisperse emulsions to be obtained. However, these proteins represent limiting situations with respect to their structure and native state stability. While BLG has a rather stable, globular (hard) structure, NaCAS proteins have a flexible (soft) random configuration. This impacts their adsorption kinetics as well as the interfacial properties that control emulsion stability. 
In presence of $\mathrm{NaCAS}$, almost full protein adsorption was observed but the obtained emulsions were subjected to unlimited coalescence. This was especially the case when the mean droplet size exceeded $1 \mu \mathrm{m}$, coalescence being facilitated by the fast creaming process. We found 3 routes to enhance stability based on a modification of the aqueous phase: addition of free proteins after emulsification; acidification, addition of calcium ions before or after emulsification. In presence of BLG, the emulsions were kinetically stable after emulsification (at the time scale of 1 month), although adsorption was only partial (a fraction of proteins remained free in the aqueous phase).

We hope the present study will provide a useful guidance for the formulation of emulsions based on proteins, with a very good control level on their droplet size distribution as well as on the amount of protein used.

\section{Acknowledgements}

This work was performed, in partnership with the SAS PIVERT, within the frame of the French Institute for the Energy Transition (Institut pour la Transition Energétique (ITE)) P.I.V.E.R.T (www.institut-pivert.com) selected as an investment for the Future («Investissement d'Avenir »). This work was supported, as a part of the Investments for the Future, by the French Government under the reference ANR-001-01. 


\section{References}

(1) McClements, D. J. Protein-Stabilized Emulsions. Current Opinion in Colloid \& Interface Science 2004, 9 (5), 305-313.

(2) Dimitrova, T. D.; Leal-Calderon, F.; Gurkov, T. D.; Campbell, B. Surface Forces in Model Oil-in-Water Emulsions Stabilized by Proteins. Advances in Colloid and Interface Science 2004, 108-109, 73-86.

(3) Mulvihill, D. M. Production, Functional Properties and Utilization of Milk Protein Products. In P. F. Fox (Ed.), Proteins. Advanced Dairy Chemistry, Vol. 1 (Pp. 369e405). London, UK: Elsevier Applied Science.

(4) Möbius, D.; Miller, R. Proteins at Liquid Interfaces; Elsevier, 1998.

(5) Dickinson, E. Adsorbed Protein Layers at Fluid Interfaces: Interactions, Structure and Surface Rheology. Colloids and Surfaces B: Biointerfaces 1999, 15 (2), 161-176.

(6) Robertson, T. B.; Greaves, J. E. On the Refractive Indices of Solutions of Certain Proteins. V. Gliadin. J Biol Chem 1911, 9 (3), 181-184.

(7) Khwaldia, K.; Banon, S.; Perez, C.; Desobry, S. Properties of Sodium Caseinate FilmForming Dispersions and Films. Journal of Dairy Science 2004, 87 (7), 2011-2016.

(8) Swaisgood, H. E. Review and Update of Casein Chemistry. J. Dairy Sci. 1993, 76 (10), 3054-3061.

(9) Pepper, L.; Farrell, H. M. Interactions Leading to Formation of Casein Submicelles. Journal of Dairy Science 1982, 65 (12), 2259-2266.

(10) Tcholakova, S.; Denkov, N. D.; Ivanov, I. B.; Campbell, B. Coalescence in $\beta$ Lactoglobulin-Stabilized Emulsions: Effects of Protein Adsorption and Drop Size. Langmuir 2002, 18 (23), 8960-8971.

(11) A. Bos, M.; van Vliet, T. Interfacial Rheological Properties of Adsorbed Protein Layers and Surfactants: A Review. Advances in Colloid and Interface Science 2001, 91 (3), 437-471.

(12) Freer, E. M.; Yim, K. S.; Fuller, G. G.; Radke, C. J. Interfacial Rheology of Globular and Flexible Proteins at the Hexadecane/Water Interface: Comparison of Shear and Dilatation Deformation. J. Phys. Chem. B 2004, 108 (12), 3835-3844.

(13) Graham, D. E.; Phillips, M. C. Proteins at Liquid Interfaces: I. Kinetics of Adsorption and Surface Denaturation. Journal of Colloid and Interface Science 1979, 70 (3), 403414. 
(14) Sengupta, T.; Razumovsky, L.; Damodaran, S. Energetics of Protein-Interface Interactions and Its Effect on Protein Adsorption. Langmuir 1999, 15 (20), 6991-7001.

(15) Tcholakova, S.; Denkov, N. D.; Sidzhakova, D.; Ivanov, I. B.; Campbell, B. Interrelation between Drop Size and Protein Adsorption at Various Emulsification Conditions. Langmuir 2003, 19 (14), 5640-5649.

(16) Narsimhan, G.; Goel, P. Drop Coalescence during Emulsion Formation in a HighPressure Homogenizer for Tetradecane-in-Water Emulsion Stabilized by Sodium Dodecyl Sulfate. Journal of Colloid and Interface Science 2001, 238 (2), 420-432.

(17) Walstra, P. Formation of Emulsions. In Encyclopedia of Emulsion Technology; Chapter 2.; Marcel Dekker: New York, 1983.

(18) Walstra, P.; Smulders, P. Congress Proceedings: First World Congress on Emulsion, 19-22 October 1993, Paris, France: Volume 3: Applications, Bitumen Emulsions, Emulsion Industries: Abstracts and Extended Papers of Theme No 4; Paris, 1993.

(19) Walstra, P.; Geurts, T. J.; Noomen, A.; Jellema, A.; van Boekel, M. A. J. S. Dairy Technology: Principles of Milk Properties and Processes, 1 edition.; CRC Press, 1999.

(20) McClements, D. J. Food Emulsions: Principles, Practices, and Techniques, Third Edition; CRC Press, 2015.

(21) Arditty, S.; Whitby, C. P.; Binks, B. P.; Schmitt, V.; Leal-Calderon, F. Some General Features of Limited Coalescence in Solid-Stabilized Emulsions. Eur. Phys. J. E 2003, $11(3), 273-281$.

(22) Whitesides, T. H.; Ross, D. S. Experimental and Theoretical Analysis of the Limited Coalescence Process: Stepwise Limited Coalescence. Journal of Colloid and Interface Science 1995, 169 (1), 48-59.

(23) Leal-Calderon, F.; Schmitt, V.; Bibette, J. Emulsion Science. Basic Principles; Springer, 2007.

(24) Mie Gustav. Beiträge Zur Optik Trüber Medien, Speziell Kolloidaler Metallösungen. Annalen der Physik 2006, 330 (3), 377-445.

(25) Bradford, M. M. A Rapid and Sensitive Method for the Quantitation of Microgram Quantities of Protein Utilizing the Principle of Protein-Dye Binding. Analytical Biochemistry 1976, 72 (1), 248-254.

(26) Wiley, R. M. Limited Coalescence of Oil Droplets in Coarse Oil-in-Water Emulsions. Journal of Colloid Science 1954, 9 (5), 427-437. 
(27) Sánchez, C. C.; Patino, J. M. R. Interfacial, Foaming and Emulsifying Characteristics of Sodium Caseinate as Influenced by Protein Concentration in Solution. Food Hydrocolloids 2005, 19 (3), 407-416.

(28) Sünder, A.; Scherze, I.; Muschiolik, G. Physico-Chemical Characteristics of Oil-inWater Emulsions Based on Whey Protein-phospholipid Mixtures. Colloids and Surfaces B: Biointerfaces 2001, 21 (1), 75-85.

(29) Broyard, C.; Gaucheron, F. Modifications of Structures and Functions of Caseins: A Scientific and Technological Challenge. Dairy Sci. \& Technol. 2015, 95 (6), 831-862.

(30) Keowmaneechai, E.; McClements, D. J. Influence of EDTA and Citrate on Thermal Stability of Whey Protein Stabilized Oil-in-Water Emulsions Containing Calcium Chloride. Food Research International 2006, 39 (2), 230-239.

(31) Riou, E.; Havea, P.; McCarthy, O.; Watkinson, P.; Singh, H. Behavior of Protein in the Presence of Calcium during Heating of Whey Protein Concentrate Solutions. J. Agric. Food Chem. 2011, 59 (24), 13156-13164.

(32) Srinivasan, M.; Singh, H.; Munro, P. A. Sodium Caseinate-Stabilized Emulsions: Factors Affecting Coverage and Composition of Surface Proteins. J. Agric. Food Chem. 1996, 44 (12), 3807-3811.

(33) Dickinson, E.; Davies, E. Influence of Ionic Calcium on Stability of Sodium Caseinate Emulsions. Colloids and Surfaces B: Biointerfaces 1999, 12 (3), 203-212.

(34) Ye, A.; Singh, H. Interfacial Composition and Stability of Sodium Caseinate Emulsions as Influenced by Calcium Ions. Food Hydrocolloids 2001, 15 (2), 195-207.

(35) Ho, C.; Waugh, D. F. Interactions of Bovine Caseins with Divalent Cations. J. Am. Chem. Soc. 1965, 87, 889-892.

(36) Perrechil, F. A.; Cunha, R. L. Oil-in-Water Emulsions Stabilized by Sodium Caseinate: Influence of $\mathrm{PH}$, High-Pressure Homogenization and Locust Bean Gum Addition. Journal of Food Engineering 2010, 97 (4), 441-448.

(37) Marichal, M. J. A. Manipulating Sodium Caseinate Behaviour at the Interface: Applications for Concentrated Emulsion Formulation: A Thesis Submitted to the Victoria University of Wellington in Fulfilment of the Requirements for the Degree of Doctor of Philosophy in Chemistry; Victoria University of Wellington, 2014.

(38) Dimitrova, T. D.; Leal-Calderon, F. Rheological Properties of Highly Concentrated Protein-Stabilized Emulsions. Advances in Colloid and Interface Science 2004, 108109, 49-61. 
(39) Cascão Pereira, L. G.; Théodoly, O.; Blanch, H. W.; Radke, C. J. Dilatational Rheology of BSA Conformers at the Air/Water Interface. Langmuir 2003, 19 (6), 2349-2356.

(40) Atkinson, P. J.; Dickinson, E.; Horne, D. S.; Richardson, R. M. Neutron Reflectivity of Adsorbed $\beta$-Casein and $\beta$-Lactoglobulin at the Air/Water Interface. J. Chem. Soc., Faraday Trans. 1995, 91 (17), 2847-2854.

(41) Bantchev, G. B.; Schwartz, D. K. Surface Shear Rheology of $\beta$-Casein Layers at the Air/Solution Interface: Formation of a Two-Dimensional Physical Gel. Langmuir 2003, 19 (7), 2673-2682.

(42) Tupy, M. J.; Blanch, H. W.; Radke, C. J. Total Internal Reflection Fluorescence Spectrometer To Study Dynamic Adsorption Phenomena at Liquid/Liquid Interfaces. Ind. Eng. Chem. Res. 1998, 37 (8), 3159-3168.

(43) Wilde, P.; Mackie, A.; Husband, F.; Gunning, P.; Morris, V. Proteins and Emulsifiers at Liquid Interfaces. Advances in Colloid and Interface Science 2004, 108-109, 63-71. 